\title{
Rice Grain Cadmium Concentrations in the Global Supply-Chain
}

\author{
Zhengyu Shi $^{1}$ - Manus Carey ${ }^{1}$. Caroline Meharg ${ }^{1} \cdot$ Paul N. Williams $^{1} \cdot$ Antonio J. Signes-Pastor $^{1}$. \\ Eridha Ayu Triwardhani ${ }^{1} \cdot$ Febbyandi Isnanda Pandiangan $^{1} \cdot$ Katrina Campbell $^{1}$. Christopher Elliott ${ }^{1}$. \\ Ernest M. Marwa ${ }^{2} \cdot$ Xiao Jiujin ${ }^{3} \cdot$ Júlia Gomes Farias $^{4} \cdot$ Fernando Teixeira Nicoloso ${ }^{4} \cdot$ P. Mangala C. S. De Silva ${ }^{5}$. \\ Ying $\mathrm{Lu}^{6} \cdot$ Gareth Norton $^{7}$. Eureka Adomako ${ }^{8}$ Andy J. Green ${ }^{9} \cdot$ Eduardo Moreno-Jiménez $^{10} \cdot$ Yongguan Zhu $^{11}$. \\ Ángel Antonio Carbonell-Barrachina ${ }^{12}$. Parvez I. Haris ${ }^{13}$. Youssef F. Lawgali ${ }^{14}$. Alessia Sommella ${ }^{15}$. \\ Massimo Pigna ${ }^{15}$. Catherine Brabet ${ }^{16} \cdot$ Didier Montet $^{16} \cdot$ Keston Njira $^{17} \cdot$ Michael J. Watts $^{18} \cdot$ Mahmud Hossain $^{19}$. \\ M. Rafiqul Islam ${ }^{19} \cdot$ Yasna Tapia $^{20} \cdot$ Carla Oporto $^{21} \cdot$ Andrew A. Meharg $^{1}$ (I)
}

Received: 8 January 2020 / Revised: 17 February 2020 / Accepted: 19 February 2020 / Published online: 2 March 2020 (c) The Author(s) 2020

\begin{abstract}
One of cadmium's major exposure routes to humans is through rice consumption. The concentrations of cadmium in the global polished (white), market rice supply-chain were assessed in 2270 samples, purchased from retailers across 32 countries, encompassing 6 continents. It was found on a global basis that East Africa had the lowest cadmium with a median for both Malawi and Tanzania at $4.9 \mu \mathrm{g} / \mathrm{kg}$, an order of magnitude lower than the highest country, China with a median at $69.3 \mu \mathrm{g} /$ $\mathrm{kg}$. The Americas were typically low in cadmium, but the Indian sub-continent was universally elevated. In particular certain regions of Bangladesh had high cadmium, that when combined with the high daily consumption rate of rice of that country, leads to high cadmium exposures. Concentrations of cadmium were compared to the European Standard for polished rice of $200 \mu \mathrm{g} / \mathrm{kg}$ and $5 \%$ of the global supply-chain exceeded this threshold. For the stricter standard of $40 \mu \mathrm{g} / \mathrm{kg}$ for processed infant foods, for which rice can comprise up to $100 \%$ by composition (such as rice porridges, puffed rice cereal and cakes), $25 \%$ of rice would not be suitable for making pure rice baby foods. Given that rice is also elevated in inorganic arsenic, the only region of the world where both inorganic arsenic and cadmium were low in grain was East Africa.
\end{abstract}

Keywords Arsenic $\cdot$ Cadmium $\cdot$ Exposure route $\cdot$ Rice

\section{Introduction}

Cadmium is a nephrotoxin and carcinogen with a half-life in the human body measured in decades (BfR 2018). A major exposure route of cadmium globally is the grains of wheat and rice (BfR 2018; EFSA 2009, 2012). An early understanding regarding the toxic effects of cadmium on human health was associated with consumption of rice elevated with cadmium (itai-itai disease) in the mid 1950s (Kobayashi 1978). Regulations regarding the maximum concentrations of cadmium allowed in wheat and rice has been set at $200 \mu \mathrm{g} / \mathrm{kg}$ in the European Union (Commission Regulation 2006). Stricter standards are set for processed baby foods in the EU, at $40 \mu \mathrm{g} / \mathrm{kg}$ (Commission Regulation

Andrew A. Meharg

aa.meharg@qub.ac.uk

Extended author information available on the last page of the article
2006). Cadmium intakes are of particular concern in China as rice grain cadmium tends to be elevated across this country (Meharg et al. 2013).

Establishing a global context for cadmium in rice is needed for regulatory standard setting, food safety advice and to develop mitigation options. For regulation it is important to understand what "normal" concentrations of cadmium in rice are, and what percentages of the global supply-chain exceed different thresholds thought to be important for health (Meharg et al. 2013). For food safety, such as minimising the exposure to sensitive populations, including as young children weaned on rice (Gardener et al. 2019), identification of low-cadmium rice sources would be an advance. For mitigation, knowing where and why cadmium is elevated in rice can further the identification of sources of this element to paddy environments, and refine management practices to lower concentrations in grain. It is through the widespread mining and processing of base metals has led 
to elevated cadmium in Chinese supplies (Chen et al. 2018; Fang et al. 2014; Hu et al. 2016; Ke et al. 2015; Mu et al. 2019; Williams et al. 2007). Thus, for example, moving rice production away from such pollution will lead to lowering of cadmium in the supply chain. Another source of cadmium pollution is the presence of cadmium in fertilisers that are widely used in rice farming (Roberts 2014). The EU has recently set limit on the content of cadmium in fertilisers to protect human health and the environment (https://data. consilium.europa.eu/doc/document/PE-76-2018-INIT/en/ pdf). For mitigation options a wide range of technologies have been investigated for lowering grain cadmium including: breeding, field-water management and immobilising amendments (Hu et al. 2016; Zhao and Wang 2020). Global patterns in rice cadmium may identify where the best management practices may be found. This is particularly true for water management where more aerobic rice cultivation leads to higher grain cadmium (Hu et al. 2016). In particular, more upland, rain-fed, production is thought to lead to cadmium elevation.

When it comes to variation in rice cadmium, besides the aforementioned surveys of China (Chen et al. 2018; Fang et al. 2014; Hu et al. 2016; Ke et al. 2015; Mu et al. 2019; Williams e al. 2007), the rest of the globe is either considered country-by-country (Adomako et al. 2011; Joy et al. 2017; Kato et al. 2019; Pastorelli et al. 2018; Rahman et al. 2014; Sommella et al. 2013; and other surveys compiled in Ke et al. 2015) or with a limited inter-country overview (Meharg et al. 2013). Here we intend to build from previous surveys (Adomako et al. 2011; Meharg et al. 2013; Joy et al. 2017; Sommella et al. 2013; Williams et al. 2007) by integrating with these previous studies new cadmium data derived from a rice survey designed to represent the global supply-chain that has been characterised for arsenic speciation (Carey et al. 2020). Importantly, these surveys cover Africa, south (S.) America, the Indian subcontinent and the south-east (S.E.) Asian archipelago, which are not well considered for cadmium in the literature. The study presented here focuses on white rice purchased from market, to represent best what is actually being consumed. All the data presented were produced in our laboratories under the same quality assurance/quality control (QA/QC) procedures.

\section{Materials and Methods}

\section{Rice Sample Collection}

Polished, locally produced, market rice, number of samples $(n)=2270$, was purchased from retailers from 32 countries from 6 continents. Surveyed regions and sampling frequency are given in Table 1. A set of previous published data published by our group, $n=1167$, have been reported for China
(Williams et al. 2007) and Bangladesh, Cambodia, France, Ghana, India, Italy, Japan, Nepal, Spain, Sri Lanka, Thailand and the USA (Adomako et al. 2011; Meharg et al. 2013; Sommella et al. 2013; Williams et al. 2007). More than 1100 new samples were reported here, including Malawian samples from Joy et al. (2017), adding depth to previously sampled regions, as well as adding new countries to the survey (Table 1). Post-harvest treatment of rice differs regionally, and sampling is biased by the geographic origin of authors, and their varying ability to systematically sample across the surveyed regions. As such, this study cannot be considered as a stratified survey, and suffers similar limitations to previously published surveys on rice nutrition (Ke et al. 2015; Meharg et al. 2013; Rahman et al., 2014). This must be born in mind when interpreting the data.

For some countries/regions the geographic clustering of the samples enables further investigation of the data. For the Americas, the main production region centres on the border of S. Brazil with $n$. Argentina, Paraguay and Uruguay, and thus these samples can be seen as geographically related. High spatial resolution was present in the Italian, Malian, Spanish and Tanzanian datasets. The Chinese data are given by province. The Indian, Nepal and Pakistan samples were all Basmati variety, and are widely available globally, and were obtained from this export market.

\section{Sample Preparation and Analysis}

Analytical protocols and performance for previous surveys are presented in the studies in which the data were first presented (Williams et al. 2007; Meharg et al. 2013). For the new batch of data, sample preparation and analysis protocols differ mainly in the in the model of ICP-MS used. The new protocols are as follows: grain samples were freeze dried and then milled to a fine powder and weighed accurately to a weight of $0.1 \mathrm{~g}$ into $50 \mathrm{ml}$ polypropylene centrifuge tubes to which $2 \mathrm{ml}$ of conc. (68\%) Aristar nitric acid was added and allowed to sit overnight. Then $2 \mathrm{ml}$ of Aristar hydrogen peroxide was added to each tube and allowed to outgas for $15 \mathrm{~min}$. Batches of up to 48 samples were prepared which also included duplicate blanks and duplicate samples of rice flour certified reference material (CRM) NIST 1568b in all analytical batches. Samples were microwave digested using a CEM MARS 6 instrument, and on cooling diluted accurately to $30 \mathrm{ml}$ with deionized distilled water, with rhodium used as an internal standard. Cadmium was quantified by ICP-MS (Thermo ICAP-Q, UK) against a standard calibration. Cadmium had a mean recovery, plus or minus standard error, of $104.4 \pm 6.1 \%, n=55$. The limits of detection (LoD) for cadmium was $9.8 \mu \mathrm{g} / \mathrm{kg}$, and $1 / 2 \mathrm{LoD}$ was assigned to all values below this value. Lower LoDs were reported for Williams et al (2007) and Meharg et al. (2013), and to avoid artefactual variance occurring, all measured values below 
Table 1 Sampling locations, and grain cadmium median, sample number $(n), 25$ th and 75th percentiles, minimum and maximum $(\mu \mathrm{g} / \mathrm{kg})$, and number of samples collected for each location

\begin{tabular}{|c|c|c|c|c|c|c|c|c|}
\hline & & $n$ & Min & $25 \%$ & Med & $75 \%$ & Max & Range \\
\hline Amer. & Mexico & 8 & 4.9 & 4.9 & 12.8 & 15.63 & 22.1 & 17.2 \\
\hline Amer. & USA & 18 & 4.9 & 13.8 & 17.05 & 20.75 & 31.8 & 26.9 \\
\hline Amer. & Argentina & 11 & 4.9 & 4.9 & 4.9 & 12.6 & 24.9 & 20 \\
\hline Amer. & Bolivia & 10 & 4.9 & 4.9 & 23.05 & 80.95 & 123.4 & 118.5 \\
\hline Amer. & Brazil & 142 & 4.9 & 4.9 & 12.2 & 17.5 & 70.6 & 65.7 \\
\hline Amer. & Chile & 15 & 4.9 & 4.9 & 4.9 & 4.9 & 4.9 & 0 \\
\hline Amer. & Paraguay & 27 & 4.9 & 4.9 & 4.9 & 4.9 & 11 & 6.1 \\
\hline Amer. & Uruguay & 7 & 4.9 & 4.9 & 4.9 & 11.5 & 37.7 & 32.8 \\
\hline Eur./Med. & Egypt & 6 & 4.9 & 4.9 & 4.9 & 4.9 & 4.9 & 0 \\
\hline Eur./Med. & France & 31 & 4.9 & 4.9 & 4.9 & 7.3 & 20 & 15.1 \\
\hline Eur./Med. & Italy & 205 & 4.9 & 12.1 & 25.7 & 43.05 & 226.2 & 221.3 \\
\hline Eur./Med. & Spain & 84 & 4.9 & 4.9 & 12.05 & 20.35 & 142.5 & 137.6 \\
\hline Eur./Med. & Turkey & 20 & 4.9 & 4.9 & 4.9 & 12.73 & 33.8 & 28.9 \\
\hline Africa, W. & Ivory Coast & 88 & 10.6 & 17.3 & 21.7 & 34.78 & 85 & 74.4 \\
\hline Africa, W. & Mali & 44 & 4.9 & 4.9 & 17.2 & 23.98 & 44.6 & 39.7 \\
\hline Africa, W. & Ghana & 426 & 4.9 & 4.9 & 13.4 & 21.93 & 267.4 & 262.5 \\
\hline Africa, E. & Malawi & 19 & 4.9 & 4.9 & 4.9 & 16.8 & 26.6 & 21.7 \\
\hline Africa, E. & Mauritius & 3 & 92.5 & 925 & 93.6 & 96.7 & 96.7 & 4.2 \\
\hline Africa, E. & Tanzania & 88 & 4.9 & 4.9 & 4.9 & 4.9 & 15.5 & 10.6 \\
\hline Asia, Ind. sub-c. & Bangladesh & 28 & 4.9 & 16.2 & 24.7 & 45.68 & 257.7 & 252.8 \\
\hline Asia, Ind. sub-c. & India & 46 & 4.9 & 10.3 & 27.55 & 43.1 & 1005 & 999.9 \\
\hline Asia, Ind. sub-c. & Nepal & 12 & 13.9 & 29.1 & 47.6 & 74.88 & 82.9 & 69 \\
\hline Asia, Ind. sub-c. & Pakistan & 3 & 31.1 & 31.1 & 33.1 & 40.2 & 40.2 & 9.1 \\
\hline Asia, Ind. sub-c. & Sri Lanka & 137 & 4.9 & 16.7 & 28.4 & 59.1 & 367.1 & 362.2 \\
\hline Asia, E. & Cantodia & 14 & 4.9 & 4.9 & 4.9 & 4.9 & 34.5 & 33.5 \\
\hline Asia, E. & China & 495 & 4.9 & 22 & 69.3 & 181 & 3712 & 3708 \\
\hline Asia, E. & Japan & 19 & 10.1 & 25.3 & 45.9 & 92 & 143.9 & 133.8 \\
\hline Asia, E. & S. Korea & 56 & 4.9 & 11.4 & 15.45 & 24.8 & 260.3 & 255.4 \\
\hline Asia, S.E. & Indonesia & 80 & 4.9 & 11.2 & 20.8 & 36.03 & 597.5 & 592.6 \\
\hline Asia, S.E. & Thailand & 20 & 11.8 & 19.7 & 22.05 & 36.3 & 52.2 & 40.4 \\
\hline Asia, S.E. & Vietnam & 107 & 4.9 & 13.3 & 19 & 34.7 & 224.8 & 219.9 \\
\hline Asia, S.E. & Australia & 8 & 4.9 & 4.9 & 4.9 & 13.9 & 29.7 & 24.8 \\
\hline
\end{tabular}

$4.9 \mu \mathrm{g} / \mathrm{kg}$ from previous surveys were allocated to the same $1 / 2 \mathrm{LoD}$ of $4.9 \mu \mathrm{g} / \mathrm{kg}$.

\section{Statistical Analysis}

All statistical analysis was performed on SPSS v. 25 (IBM, USA). The Kruskal-Wallis test was used to test medians between sample groups.

\section{Results}

Globally, cadmium in white rice varied from $<4.9$ to $3712 \mu \mathrm{g} / \mathrm{kg}$, with a global median of $19.0 \mu \mathrm{g} / \mathrm{kg}$ (Table 1 , Fig. 1). The median value of cadmium in grain significantly varied between regions $(p<0.001)$. American regions had low medians, with 4 countries medians at the LoD.
Only Bolivia exceeded the global median at $23.0 \mu \mathrm{g} / \mathrm{kg}$. Kruskal-Wallis test found highly significant differences $(p<0.0001)$ between all American countries, and for those with neighbouring rice cultivation areas (Argentina, Brazil, Paraguay and Uruguay). The cadmium in rice for the European/ Mediterranean region was also low, with both Egypt and Turkey having median cadmium concentrations at the LoD, being highly significantly different $(p<0.0001)$. Only Italy, at $25.7 \mu \mathrm{g} / \mathrm{kg}$, exceeded the global median. African rice was, on the whole, low for grain cadmium, with median concentrations for Malawi and Tanzania being at the LoD, and with only Mauritius having high concentrations with a median of $93.6 \mu \mathrm{g} / \mathrm{kg}$, greater than 4-times that of the global median. There were highly significant differences ( $p<0.0001)$ within East and West Africa regions. The situation changes for the Indian subcontinent where all medians were above the global median, with Nepal recording 
Fig. 1 Median concentrations of cadmium in white (polished) rice across the globe. Bars represent the 25th and 75th percentiles. The dashed lines are for the EU standards (Commission Regulation 2006) for polished rice grain $(200 \mu \mathrm{g}$ / $\mathrm{kg}$ ) and processed infant foods $(40 \mu \mathrm{g} / \mathrm{kg})$

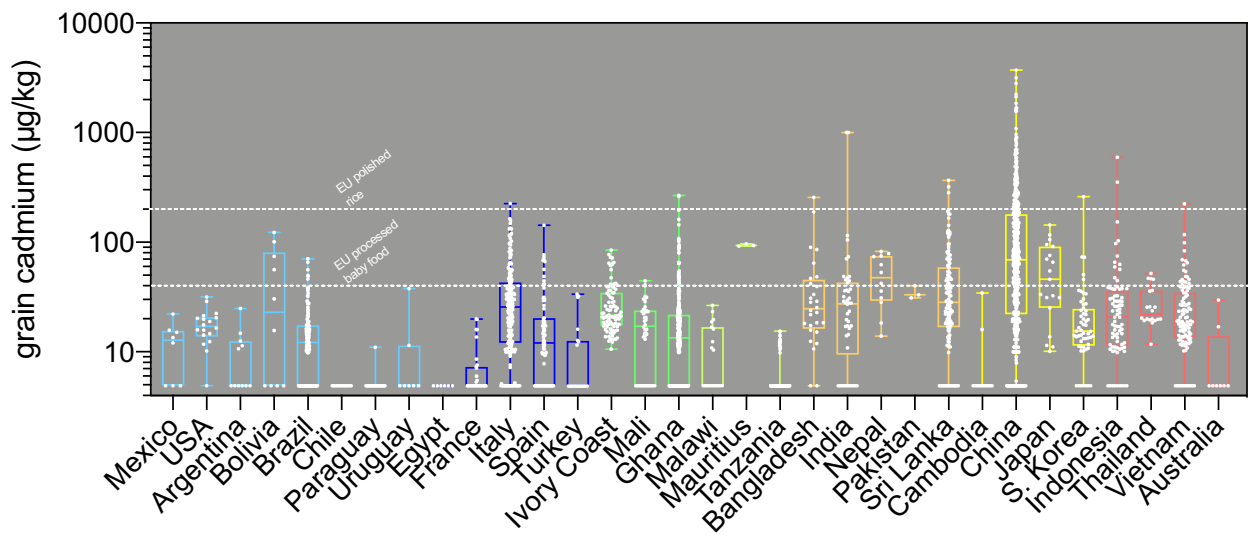

the highest median at $47.6 \mu \mathrm{g} / \mathrm{kg}$. There were no significant differences between Indian subcontinent rice $(p=0.182)$. Highest medians globally by country were recorded for E. Asia, China at $93.3 \mu \mathrm{g} / \mathrm{kg}$ and Japan at $45.9 \mu \mathrm{g} / \mathrm{kg}$, with highly significant differences between the 3 countries in this region, with South Korea being the lowest $(p<0.0001)$. S.E. Asian countries were also highly significantly different from each other. Considering the range of the data (Fig. 1), Ivory Coast, Mauritius, Nepal, Pakistan and Thailand were the only countries not to have concentrations of cadmium less than LoD for any sample (Fig. 2). The Ivory Coast, in particular, had close clustering, i.e. uniformity, in grain cadmium with content, given that it also had good sampling depth $(n=88)$, with the 25 th and 75 th percentile being 17.3 and $34.8 \mu \mathrm{g} / \mathrm{kg}$, respectively.

With respect to intra-country differences, only Mali $(p=0.078)$ had non-significant differences between regions (Fig. 2). The greatest contrasts between regions were observed for Bangladesh and China. For Bangladesh, Mymensingh had 3 or greater times median cadmium ( 90. $2 \mu \mathrm{g} / \mathrm{kg}$ ) than other districts. For China only Hainan and Nanjing had relatively low grain cadmium, with medians of 39 and $16 \mu \mathrm{g} / \mathrm{kg}$, respectively. This contrasts, for example, with Guangxi province where the median was highest at $209 \mu \mathrm{g} / \mathrm{kg}$.

When relating the observed grain cadmium to EU standards. For all regions except China, less than $5 \%$ of samples exceed the $200 \mu \mathrm{g} / \mathrm{kg}$ EU limit (Fig. 2). No American sample exceeded this limit, and only 1 European sample, 2 African, 6 Indian subcontinent and 3 S.E. Asian exceeded the standard (Fig. 2). For China $17 \%$ of samples were in exceedance. For the lower processed baby food standard of $40 \mu \mathrm{g} / \mathrm{kg}$, most regions had a substantial portion over that concentration, with the exception of East Africa, although the few samples from Mauritius were all high. When considered by country, there was considerable variation in exceeding the $40 \mu \mathrm{g} / \mathrm{kg}$ standard. Bolivian rice was high (though sampling was limited), while Brazil also had 5 samples that exceeded this limit. For Europe/Mediterranean, Spain, and Italy in particular had a high number of samples above $40 \mu \mathrm{g} / \mathrm{kg}$. The Ivory Coast and Ghana also had samples above $40 \mu \mathrm{g} /$ $\mathrm{kg}$. For the Indian subcontinent only, Pakistan had all samples below $40 \mu \mathrm{g} / \mathrm{kg}$. For E. Asia, only Cambodia had all samples below this threshold, and only Australia for the S.E. Asian archipelago, which the Australasian continent is considered part of here. For China, only $43 \%$ of the samples were below $40 \mu \mathrm{g} / \mathrm{kg}$ (Fig. 3).

To consider how cadmium relates to arsenic, the other major global issue with respect to the global rice supply food-chain, median cadmium and inorganic arsenic concentrations were compiled from this survey of cadmium and related to arsenic speciation (Carey et al. 2020) for countries were both parameters were available. The cadmium versus inorganic arsenic plot is shown in Fig. 4. There was no relationship, when considering medians, between grain cadmium and inorganic arsenic. What stands out is that paddy rice has a tendency to be low in cadmium, but high in inorganic arsenic. The exceptions are Tanzania and Malawi which are very low in both cadmium, and inorganic arsenic; Sri Lanka which is intermediate in both, and China which is high in these two toxicants.

\section{Discussion}

Cadmium concentrations in rice have been well investigated for China (Chen et al. 2018; Fang et al. 2014; Hu et al. 2016; Ke et al. 2015; Mu et al. 2019; Williams et al. 2007). Intra-country comparisons are normally restricted to literature compilation of diverse studies (Ke et al. 2015), although there have been limited intra-country comparisons (Meharg et al. 2013). Individual country studies have been useful with respect to development of cadmium in rice as a research area for investigation, particularly with respect to informing regulation of this element in the human diet (BfR 2018; Commission Regulation 2006; EFSA 2009, 2012). However, such surveys do not enable a comprehensive analysis of the global supply-chain. Thus, 


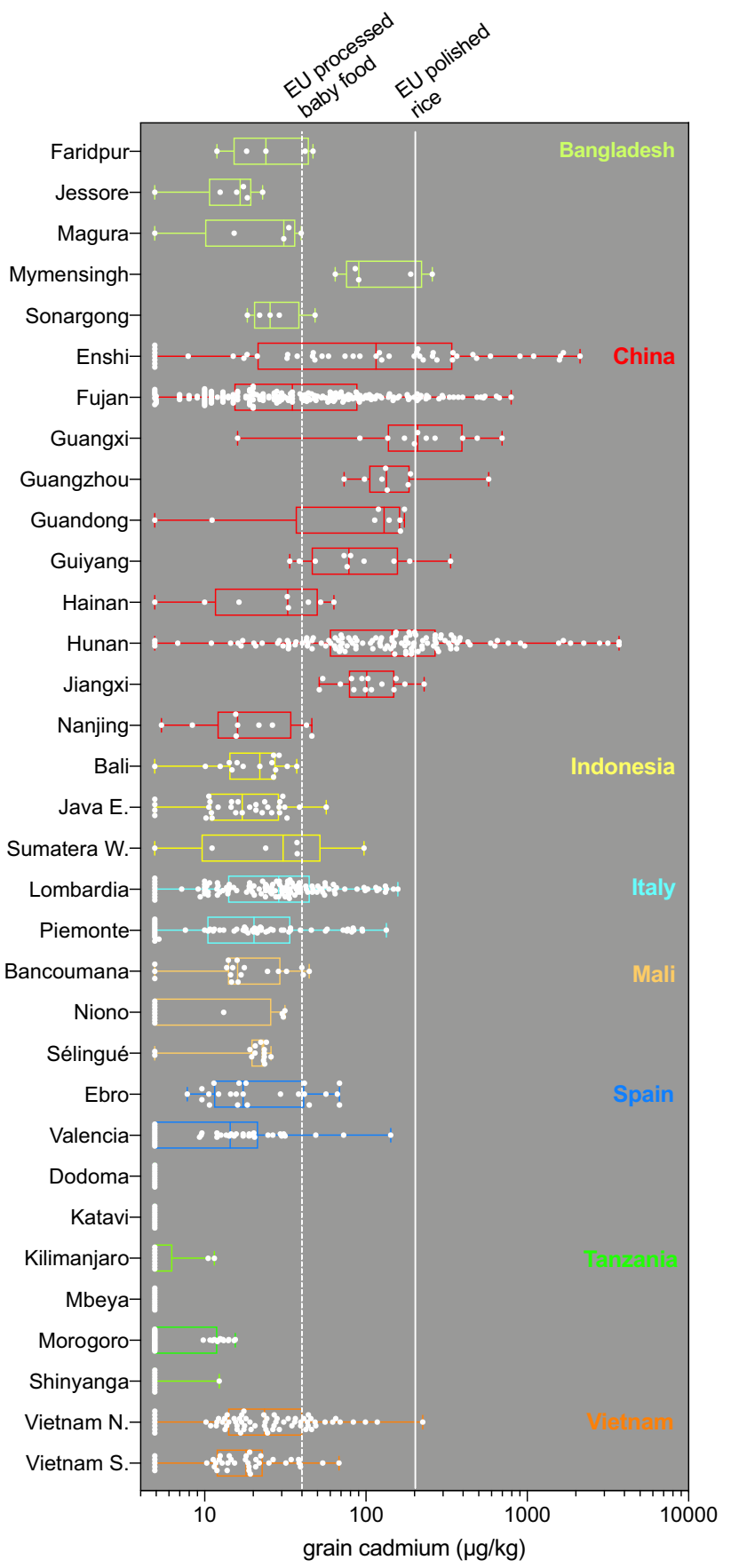

Fig. 2 Median concentrations of cadmium in white (polished) rice comparisons within country where available. Bars represent the 25 th and 75 th percentiles

this wide reaching survey presented here, where samples were analysed under the same operating procedures and CRMs, provides a more robust overview of cadmium in rice globally. In particular, the approach presented here allows consistent reporting of medians, where means only are often reported in the literature (Ke et al. 2015). This is important as cadmium in rice is not normally distributed

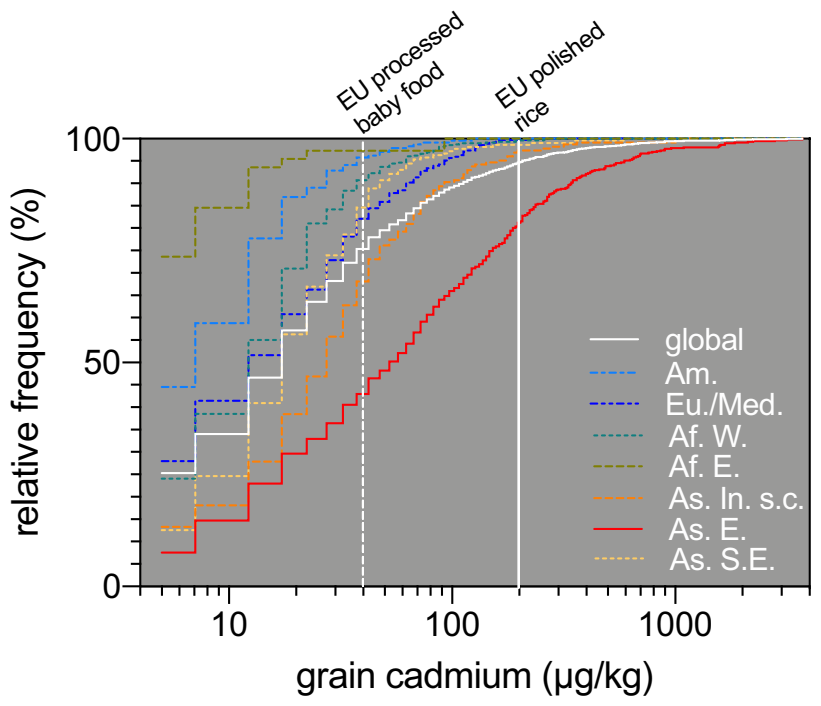

Fig. 3 Cumulative relative frequencies of cadmium concentrations in white (polished) rice for each region surveyed. The dashed lines are for the EU standards (Commission Regulation 2006) for polished rice grain $(200 \mu \mathrm{g} / \mathrm{kg})$ and processed infant foods $(40 \mu \mathrm{g} / \mathrm{kg})$

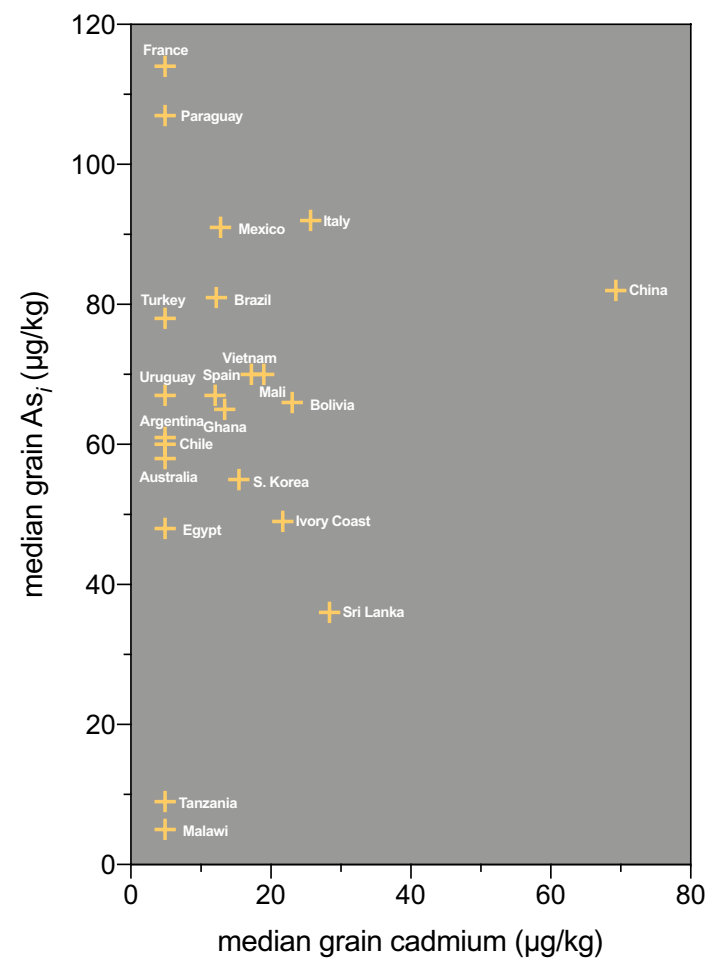

Fig. 4 Comparison, where available, for country medians for cadmium reported here and inorganic arsenic from Carey et al. (2020)

and, thus, reporting of means is statistically inappropriate. Importantly, having a unified dataset enables appropriate statistical interpretation of the data, which cannot be conducted from literature compilations, especially 
as individual sample concentrations are normally not presented.

The strengths of the approach undertaken here and noted need to be balanced by the fact that many cadmium-in-rice surveys, including the current investigation, have generally unbalanced sampling designs. To achieve a globally balanced sampling design is unattainable without considerable resources. Within country survey can be better achieved, but even then there tends to be a bias towards high production areas (Chen et al. 2018). High production areas are more important with respect to human consumption, but if the survey is to determine where high or low regions are, then as many samples should be taken from low production areas as high. This, to date, has to be conducted. Also, each region/ country may have different networks of milling and marketing, at a household/village level or for urban consumption, for example, leading to further layers of complexity with respect to how to adequately sample the rice supply-chain, locally, regionally and globally. However, non-systematic surveys are highly useful in establishing a basis on which to conduct further surveys, and provide an initiation point for risk assessment and mitigation. The utility of surveys conducted to date is illustrated by repeated Chinese surveys (Chen et al. 2018; Fang et al. 2014; Hu et al. 2016; Ke et al. 2015; Mu et al. 2019; Williams et al. 2007), conducted by different organisations, which reinforce each other in showing that Chines rice is elevated with respect to legislative standards, and that southern Chinese regions tend to be more elevated than northern. This is generally attributed to the fact that the southern Chinese provenances tend to be more impacted by the extensive base metal ore exploitation that occurs in these regions. While countries outside China have been less considered, the results presented here equate to those that have been published for rice from Australia, India, Italy, Bangladesh, Thailand, and Japan (Rahman et al., 2014) as well as Brazil (Kato et al. 2019) and Italy (Pastorelli et al. 2018). All these studies, including the global survey presented here, illustrate that south-eastern Chinese provinces are the highest, so far surveyed, with respect to grain cadmium.

While industrial contamination may be part of the explanation with respect to why grain cadmium is high in China, it does not explain the Indian subcontinent, across the whole region from Sri Lanka to Bangladesh, is generally high in grain cadmium. Yet, on the whole, the Indian sub-continent is less industrialised, and with less reliance from base metal mining and processing which is a major source of cadmium, and relatively distant from global sources of cadmium pollution. The content of cadmium in fertilisers also requires consideration (Roberts, 2014). Other factors such as bedrock geology, soil formation and weathering, rice genetics and paddy soil management also play a key role with respect to grain cadmium levels (Hu et al. 2016; Zhao and Wang 2020).
However, a definitive answer to the key contributors to grain cadmium has to be found.

Establishing cadmium concentrations in rice is an important part in assessing the risk posed by dietary exposure, but it has to be considered with respect to rice consumption rates (BfR 2018; EFSA 2009, 2012; Gardener et al. 2019). Thus, although there has been a lot of focus on south-eastern China, but when consumption rates are taken into account the Mymensingh region of Bangladesh looks just as problematic. A typical rice consumption rate of a Bangladesh and Chinese adult is 0.45 and $0.22 \mathrm{~kg} / \mathrm{day}$ ( $\mathrm{Hu}$ et al. 2016; Meharg et al. 2013), respectively; while grain cadmium is $90 \mu \mathrm{g} / \mathrm{kg}$ for Bangladesh as opposed to $\sim 200 \mu \mathrm{g} / \mathrm{kg}$ for the highly impacted regions of south-east China. That is, the actual cadmium intake rates will be similar between Mymensingh and south-east China, both at $40 \mu \mathrm{g} / \mathrm{d}$. Compared to China, Bangladesh is greatly understudied with respect to cadmium (Al-Rmalli et al, 2012), and this needs to be rectified. Note that EU standards are for a region where circa. $20 \mathrm{~g} /$ day rice consumption is typical, an order of magnitude lower than what is typically observed in the Indian sub-continent and S.E. Asia (Meharg et al. 2013).

Particularly of concern from cadmium exposure are infants, and stricter standards are in place in the EU for cadmium in processed baby foods $(40 \mu \mathrm{g} / \mathrm{kg})$ than for rice $(200 \mu \mathrm{g} / \mathrm{kg})$ (Commission Regulation 2006). Yet, processed foods specifically marketed at infants can be almost entirely rice, such as rice porridges and crackers, or be a major component of mixed cereal products such as porridges, snack bars rice cakes and muesli (Carey et al 2018). Thus, the finding that rice from many sources has a $10 \%$ failure rate at the infant food standard here is concerning. Only the Americas and East Africa had low percentages above this standard. Of particular relevance is the EU where the $40 \mu \mathrm{g} / \mathrm{kg}$ standard is a legal requirement (Commission Regulation 2006). Nearly $20 \%$ of EU rice tested failed this standard, meaning it would be unsuitable for use into making pure rice porridges and crackers. While $80 \%$ fall under the standard, to ensure that the standard is not breached, there is a requirement to extensively test rice at a commercial level for infant products with a high rice content to ensure compliance and food safety.

As both arsenic and cadmium are problematic in rice, and can be dually elevated (Zhao and Wang 2020) they should be considered together for the risks posed to target populations. This is particularly important for the sourcing of rice for infant foods where arsenic and cadmium pose greater risks to children (Carey et al. 2018; Gardener et al. 2019), and where children are more exposed to dietary contaminants due to higher food consumption rates on a biomass basis (Carey et al. 2018; Gardener et al. 2019). To lower the contaminants that an infant is exposed to is obviously the best situation, given the uncertainties around risk assessment and standard setting. Therefore, we have identified here the 
best source of low cadmium and arsenic rice, namely Tanzania and Malawi. Nowhere else comes close to these two regions. Other east African regions may be similarly low in cadmium and arsenic, but this needs to be further explored. Furthermore, east African rice paddies may provide solutions to producing low arsenic and cadmium rice elsewhere and an investigation into soil properties, paddy management practice and cultivars grown may hold the key to producing less contaminated crops elsewhere.

Acknowledgements We thank Edward Joy for the Malawian samples used in this study, Gökçen Akgül for the Turkish samples and Raul Ochoa Hueso for the Mexican samples.

Open Access This article is licensed under a Creative Commons Attribution 4.0 International License, which permits use, sharing, adaptation, distribution and reproduction in any medium or format, as long as you give appropriate credit to the original author(s) and the source, provide a link to the Creative Commons licence, and indicate if changes were made. The images or other third party material in this article are included in the article's Creative Commons licence, unless indicated otherwise in a credit line to the material. If material is not included in the article's Creative Commons licence and your intended use is not permitted by statutory regulation or exceeds the permitted use, you will need to obtain permission directly from the copyright holder. To view a copy of this licence, visit http://creativecommons.org/licenses/by/4.0/.

\section{References}

Adomako EA, Williams PN, Deacon C, Meharg AA (2011) Inorganic arsenic and trace elements in Ghanaian grain staples. Environ Pollut 159:2435-2442

Al-Rmalli SW, Jenkins RO, Haris PI (2012) Dietary intake of cadmium from Bangladeshi foods. J Food Sci 77:26-33

BfR Opinion No. 026/2018 (2018) EU maximum levels for cadmium in food for infants and young children sufficient-exposure to lead should fundamentally be reduced to the achievable minimum. https://doi.org/10.17590/20181205-132313-0

Carey M, Donaldson E, Signes-Pastor AJ, Meharg AA (2018) Dilution of rice with other gluten free grains to lower inorganic arsenic in foods for young children in response to European Union regulations. PLoS ONE 13:e01947000

Carey M, Meharg C, Williams P, Marwa E, Jiujin X, Gomes Farias J, De Silva PMCS, Signes-Pastor A, Lu Y, Nicoloso FT, Savage L, Campbell K, Elliott C, Adomako E, Green AJ, Moreno-Jiménez E, Carbonell-Barrachina AA, Triwardhani EA, Pandiangan FI, Haris PI, Lawgali YF, Sommella A, Pigna M, Brabet C, Montet D, Njira K, Watts MJ, Meharg AA (2020) Global sourcing of low-inorganic arsenic rice grain. Expos Health. https://doi. org/10.1007/s12403-019-00330-y

Chen H, Tang Z, Wang P, Zhao FJ (2018) Geographical variations of cadmium and arsenic concentrations and arsenic speciation in Chinese rice. Environ Pollut 238:482e490

Commission Regulation (EC) No 1881/2006 (2006) Setting maximum levels for certain contaminants in foodstuffs. https://eur-lex.europ a.eu/legal-content/EN/TXT/?uri=CELEX:02006R1881-20150521

European Food Safety Authority (2009) Scientific opinion of the panel on contaminants in the food-chain. EFSA J 980:1-139

European Food Safety Authority (2012) Cadmium dietary exposure in the European population. EFSA J 10:2551
Fang Y, Sun X, Yang W, Ma N, Xin Z, Fu J, Liu X, Liu M, Mariga AM, Zhu X, Hu Q (2014) Concentrations and health risks of lead, cadmium, arsenic, and mercury in rice and edible mushrooms in China. Food Chem 147:147-151

Gardener H, Bowen J, Callan SP (2019) Lead and cadmium contamination in a large sample of United States infant formulas and baby foods. Sci Total Environ 651:822-827

Hu P, Ouyang Y, Wu L, Shen L, Luo Y, Christie P (2015) Effects of water management on arsenic and cadmium speciation and accumulation in an upland rice cultivar. J Environ Sci 27:225-231

$\mathrm{Hu}$ Y, Cheng H, Tao S (2016) The challenges and solutions for cadmium-contaminated rice in China: a critical review. Environ Intern 92-93:515-532

Joy EJM, Ander EL, Broadley MR, Young SS, Chilimba ADC, Hamilton EM, Watts MJ (2017) Elemental composition of Malawian rice. Environ Geochem Health 39:835-845

Kato LS, De Nadai Fernandes EA, Raab A, Bacchi MA, Feldmann J (2019) Arsenic and cadmium contents in Brazilian rice from different origins can vary more than two orders of magnitude. Food Chem 286:644-650

Ke S, Cheng XY, Zhang N, Hu HG, Yan Q, Hou LL, Sun X, Chen $\mathrm{ZN}$ (2015) Cadmium contamination of rice from various polluted areas of China and its potential risks to human health. Environ Monit Assess 187:408

Kobayashi J (1978) Pollution by cadmium and the itai-itai disease in Japan. In: Oehme FW (ed) Toxicity of heavy metals in the environment. Marcel Dekker Inc., New York, pp 199-260

Meharg AA, Norton G, Deacon C, Williams P, Adomako EE, Price A, Zhu YG, Li G, Zhao FJ, McGrath S, Villada A, Sommella A, De Silva PM, Brammer H, Dasgupta T, Islam R (2013) Variation in rice cadmium related to human exposure. Environ Sci Technol 47:5613-5618

Mu T, Wu T, Zhou T, Li Z, Ouyang Y, Jiang J, Zhu D, Hou J, Wang Z, Luo Y, Christie P, Wu L (2019) Geographical variation in arsenic, cadmium, and lead of soils and rice in the major rice producing regions of China. Sci Total Environ 677:373-381

Pastorelli AA, Angeletti R, Binato G, Mariani MB, Cibin V, Morelli S, Ciardullo S, Stacchini P (2018) Exposure to cadmium through Italian rice (Oryza sativa L.): consumption and implications for human health. J Food Comp Anal 69:115-121

Rahman MA, Rahman MM, Reichman SM, Lim RP, Naidu R (2014) Heavy metals in Australian grown and imported rice and vegetables on sale in Australia, Health hazard. Ecotox Environ Saf 100:53-60

Roberts TL (2014) Cadmium and phosphorous fertilizers: the issues and the science. Proc Eng 83:52-59

Sommella A, Deacon C, Norton G, Pigna M, Violante A, Meharg AA (2013) Total arsenic, inorganic arsenic, and other elements concentrations in Italian rice grain varies with origin and type. Environ Pollut 181:38-43

Williams PN, Raab A, Feldmann J, Meharg AA (2007) Market basket survey shows elevated levels of As in south central U.S. processed rice compared to California: consequences for human dietary exposure. Environ Sci Technol 41:2178-2183

Zhao FJ, Wang P (2020) Arsenic and cadmium accumulation in rice and mitigation strategies. Plant Soil. https://doi.org/10.1007/s1110 4-019-04374-6

Publisher's Note Springer Nature remains neutral with regard to jurisdictional claims in published maps and institutional affiliations. 


\section{Affiliations}

Zhengyu Shi $^{1} \cdot$ Manus Carey ${ }^{1}$. Caroline Meharg ${ }^{1} \cdot$ Paul N. Williams $^{1} \cdot$ Antonio J. Signes-Pastor $^{1}$.

Eridha Ayu Triwardhani ${ }^{1} \cdot$ Febbyandi Isnanda Pandiangan $^{1} \cdot$ Katrina Campbell $^{1}$. Christopher Elliott ${ }^{1}$.

Ernest M. Marwa ${ }^{2} \cdot$ Xiao Jiujin ${ }^{3}$. Júlia Gomes Farias ${ }^{4} \cdot$ Fernando Teixeira Nicoloso $^{4}$. P. Mangala C. S. De Silva ${ }^{5}$. Ying $\mathrm{Lu}^{6} \cdot$ Gareth Norton $^{7}$. Eureka Adomako ${ }^{8}$. Andy J. Green ${ }^{9} \cdot$ Eduardo Moreno-Jiménez $^{10}$. Yongguan Zhu ${ }^{11}$. Ángel Antonio Carbonell-Barrachina ${ }^{12} \cdot$ Parvez I. Haris $^{13}$. Youssef F. Lawgali ${ }^{14}$. Alessia Sommella ${ }^{15}$. Massimo Pigna ${ }^{15} \cdot$ Catherine Brabet $^{16} \cdot$ Didier Montet $^{16} \cdot$ Keston Njira $^{17} \cdot$ Michael J. Watts $^{18} \cdot$ Mahmud Hossain $^{19}$. M. Rafiqul Islam ${ }^{19} \cdot$ Yasna Tapia $^{20} \cdot$ Carla Oporto $^{21} \cdot$ Andrew A. Meharg $^{1}$

1 Institute for Global Food Security, Biological Sciences, Queen's University Belfast, 19 Chlorine Gardens, Belfast BT9 5DL, Northern Ireland

2 Department of Soil \& Geological Sciences, Sokoine University of Agriculture, P. O. Box 3008, Morogoro, Tanzania

3 Sichuan Agricultural University, Chengdu 611130, Sichuan, People's Republic of China

4 Departamento de Biologia, Centro de Ciências Naturais E Exatas, Universidade Federal de Santa Maria, Santa Maria, RS 97105-900, Brazil

5 Department of Zoology, University of Ruhuna, Matara 81000, Sri Lanka

6 College of Natural Resources and Environment, South China Agricultural University, Guangzhou 510642, People's Republic of China

7 School of Biological Sciences, University of Aberdeen, Cruickshank Bld., St Machar Dr, Aberdeen AB9 3UU, Scotland

8 Department of Plant and Environmental Biology, University of Ghana, P. O. Box LG 55, Legon, Accra, Ghana

9 Department of Wetland Ecology, Estación Biológica de Doñana-CSIC, C/ Américo Vespucio 26, 41092 Sevilla, Spain

10

Department of Agricultural and Food Chemistry, Faculty of Sciences, Universidad Autónoma de Madrid, 28049 Madrid, Spain
11 Institute for Urban Ecology, 1799 Jimei Rd, Xiamen 361021, China

12 Grupo Calidad Y Seguridad Alimentaria, Departamento Tecnología Agroalimentaria, Universidad Miguel Hernández de Elche, 03312 Orihuela, Alicante, Spain

13 Faculty of Health \& Life Sciences, De Montfort University, Leicester LE1 9BH, UK

14 Faculty of Biomedical Technology, University of Benghazi, Benghazi, Libya

15 Dipartimento Di Agraria, Università Degli Studi Di Napoli Federico II, Via Università 100, 80055 Portici, NA, Italy

16 CIRAD, UMR Qualisud, TA B95/16, 73 rue Jean-François Breton, 34398 Montpellier Cedex 5, France

17 Lilongwe University of Agriculture and Natural Resources, P.O. Box 219, Lilongwe, Malawi

18 British Geological Survey, Keyworth, Nottingham NG12 5GG, England

19 Department of Soil Science, Bangladesh Agricultural University, Mymensingh 2202, Bangladesh

20 Departamento de Ingeniería Y Suelos, Facultad de Ciencias Agronómicas, Universidad de Chile, Casilla 1004, Santiago, Chile

21 Centre for Water and Environmental Sanitation, University of Mayor de San Simón, Cochabamba, Bolivia 